\title{
THE AVAILABILITY OF CUES FOR WORD \\ SEGMENTATION AND VOCABULARY \\ ACQUISITION IN CATALAN CHILD-DIRECTED SPEECH'
}

\author{
LA ACCESIBILIDAD DE INFORMACIÓN PARA LA \\ SEGMENTACIÓN DE PALABRAS Y ADQUISICIÓN DE \\ VOCABULARIO EN EL HABLA DIRIGIDA A LOS NIÑOS \\ EN CATALÁN
}

\author{
SARA FEIJÓO \\ Universidad de Barcelona. Barcelona, España. \\ sfeijoo@ub.edu

\section{JOSEPH HILFERTY} \\ Universidad de Barcelona. Barcelona, España. \\ hilferty@ub.edu
}

\section{ABSTRACT}

Several previous studies have already pointed out the usefulness of child-directed speech for several tasks during the language acquisition process. In particular, recent research suggests that the kind of structural and lexical simplifications found in the type of language especially addressed to language learning infants (i.e. utterance length and lexical redundancy) are particularly useful for preverbal infants' initial word segmentation of the speech stream. While most research conducted to date is based on English data, little is known about the facilitation effects that child-directed speech might have in other languages. The present study aims at providing cross-linguistic evidence for the usefulness of child-directed speech by analyzing speech samples addressed to Catalan-learning children.

Keywords: Word segmentation, vocabulary learning, child-directed speech, isolated words.

\section{RESUMEN}

Varios estudios previos han señalado ya la utilidad del tipo de lenguaje que las madres

* Acknowledgements: This paper has been carried out with the help provided for the project FFI2010-21478 from the Spanish Ministry of Science and Innovation (MICINN), as well as the project 2009SGR137 from the Catalan Autonomous Government. 
utilizan para dirigirse a sus hijos en el aprendizaje de lenguas, ya que dicho lenguaje ha demostrado ser de ayuda en varias de las tareas a las que los aprendices de primeras lenguas se enfrentan. En concreto, investigaciones recientes sugieren que el tipo de simplificaciones estructurales y léxicas a las que los niños están expuestos (es decir, la longitud de los enunciados maternos y la redundancia léxica en su discurso) son particularmente útiles para una segmentación inicial de palabras en el discurso oral. Mientras que la mayoría de los estudios se centran en el inglés, se sabe poco acerca de las características y los efectos que el discurso materno puede tener en otras lenguas. El presente estudio tiene como objetivo aportar evidencia de la utilidad del discurso materno en catalán a partir del análisis de fragmentos del lenguaje dirigido a niños aprendices de esta lengua.

Palabras clave: Segmentación de palabras, aprendizaje léxico, lenguaje materno, palabras aisladas.

Recibido: 30/07/2011. Aceptado: 02/09/2012.

\section{INTRODUCTION}

The linguistic mainstream has typically modelled the way infants acquire knowledge of their native language based on input understood as strings of words, rather than strings of sounds. However, accurate representations of strings of words are certainly very difficult for prelinguistic infants to achieve, and yet without accurate identification of words or morpheme boundaries, syntax acquisition cannot proceed: without words, there simply can be no syntax (Hilferty, 2003).

Hence, one of the first problems that language learners have to face is the continuous nature of the speech stream. Speech lacks consistent physical markers of the location of word boundaries: words in fluent speech are not separated by pauses, or signaled by any other consistent feature occurring only at word onsets or endings (Aslin, Woodward, LaMendola \& Bever, 1996; Cole \& Jakimik, 1980). The fact that there are no consistent boundaries raises a difficult problem for children, who must anyway determine which sound strings are words and which are not.

Models of adult speech perception state that knowledge of certain lexical units helps in the identification of word boundaries. Besides, adults are able to use semantic, syntactic, and discourse information in order to recognize and parse words from the speech stream (Fisher \& Church, 2001). This poses a difficult problem, when applying this model to younger learners: to learn the language, one must parse the speech stream first, but parsing the speech stream requires knowledge of the language. Young learners will obviously lack such knowledge and will understand little or nothing of the surrounding linguistic context. Therefore, word 
identification is a formidable task, with success far from guaranteed for preverbal children. How do infant language learners manage to segment the speech stream into sequences of distinct words and recognize words in fluent speech?

An important part of the language-acquisition problem certainly requires learning from the environment. Recent research indicates that children solve many complex language-learning problems during their first year of life, as they attune their perceptual skills to the sound structure of their native language (Saffran, Newport \& Aslin, 1996; Kuhl, 2000).

Identifying word boundaries in fluent speech must also be an input- or datadriven task, at least in large part, since the structure of words and the constraints on what constitutes a syllable are so variable across languages that it is difficult to imagine how innate knowledge could solve this problem. In this sense, the most an infant could be born with would be the expectation that words actually exist, that is, that communicative messages can be delivered by means of linguistic chunks made up of smaller discrete units. Other than that, there can be no specific expectations as to the actual structure of words. Thus, infants at the preverbal stage cannot have any a priori set of words or word templates on which to build a lexicon.

Be this as it may, the word-segmentation problem must be solved, at least in part, by an interaction between infants' learning mechanisms and the particular language input the child is exposed to. In which way is child-directed speech useful for the purpose of word segmentation? We turn to this question in the following section.

\section{INFANTS' INPUT AND THE WORD-SEGMENTATION TASK}

Words enter the infant's lexicon, and they are later used to form syntactic units like phrases and sentences, only after they have been identified as distinct sound patterns in the speech stream. Identification of words would probably not be so difficult if, during language acquisition, words were presented one at a time for the infant learner.

In fact, one of the solutions that have been proposed in the literature to the word-segmentation problem is that the child avoids the word-segmentation task by learning those words which are presented in isolation. This solution, then, places the burden of the segmentation task on the speakers who generate the infant's language input. Thus, the structural properties typical of child-directed speech appear to be a crucial element that might help infants to locate word boundaries.

Hypotheses about the possible contributions of child-directed speech to language development have been strongly criticised and undermined by linguistic nativists. In particular, the nativist argument from the "Poverty of the Stimulus" 
states that complex linguistic forms develop extremely fast and the input available to any language learner is both incomplete and sparsely represented. For nativists, linguistic knowledge is perfect, and it is impossible to extract perfect knowledge from the imperfect and degenerate data that constitutes language input (Anderson \& Lightfoot, 1999; 2002; Crain \& Pietroski, 2001). Thus, research on the role of input in language acquisition appears to have no theoretical implications for nativists. In Chomsky's own words,

(...) the investigation of mother-child interaction is bound to have virtually no consequences, and in fact it has produced no significant results, predictably. The reason people do it is that it is easy to do. You can do it if you know nothing. You don't have to understand anything about language or children, you just sit there and get data about the mother-child interaction, analyze the data and publish books about it (...) it is guaranteed to go nowhere (Chomsky, 1984: 47).

However, the study of child-directed speech has recently proved to be quite fruitful for the understanding of language development, given that the natural form of child-directed speech is modified in ways that logically facilitate infants' attempts to build initial representations for language. Thus, for instance, findings from studies of neural activity suggest that one-year-old infants attend more to child-directed speech than to adult-directed speech. This suggests that childdirected speech acts as an indicator of potentially meaningful streams of speech and it triggers brain activity in very young infants (Zangl \& Mills, 2007). Furthermore, adults have been reported to be more fluent when they talk to young children than in adult-to-adult interactions, as there are fewer false starts, mispronunciations or hesitations in child-directed speech (Sachs, Brown \& Salerno, 1976; Snow \& Ferguson, 1977).

Child-directed speech has also been shown to facilitate language-related tasks such as word segmentation. For example, Plunkett (1993) found that mothers' use of imprecise articulation correlated with their children's tendency to use more formulaic forms and unsegmented or missegmented chunks, while the prosodically exaggerated style of child-directed speech made accurate segmentation of the speech stream easier for children. Thiessen, Hill \& Saffran (2005) have also shown that the linguistic features of child-directed speech facilitate infants' detection of statistical regularities in the stream of speech (see also Thiessen \& Saffran, 2007 or Werker, Pons, Dietrich, Kajikawa, Fais \& Amano, 2007).

Along similar lines, Bernstein Ratner (1996) has suggested that the length and structure of child-directed speech makes the word-segmentation task very easy for children to perform (Bernstein Ratner, 1996; Bernstein Ratner \& Rooney, 2001). Specifically, children are most likely to encounter the items that appear in their initial lexicons in single-word utterances addressed to them. This provides 
children with a very advantageous form of input, since in one-word utterances there are no segmentation decisions to make. Then, lexical items appearing in single-word utterances are further likely to be embedded in other extremely short utterances (i.e. two- and three- word utterances). Thus, being familiar with lexical units presented first in isolation (e.g. cookie) provides the child with information about the boundaries of such units. Such information can be then used to segment units in slightly longer utterances (e.g. yummy cookie), which, in turn, can be used to segment longer strings.

In order to test their hypothesis, Bernstein Ratner \& Rooney (2001) analyzed examples of interactions between mothers and children who were in a very late preverbal stage. Data came from the Bernstein corpus of the CHILDES database. They first worked out the frequency of very short utterances (defined as utterances 1-3 words long), which should present language learners with very few segmentation decisions to take, or none at all. From all the maternal utterances analyzed, 24\% consisted of a single word, 16\% were two words long and 19\% were three words long. Thus, 59\% of child-directed utterances in the sample were three words long or less (Bernstein Ratner \& Rooney, 2001: 72-73).

Next, Bernstein Ratner \& Rooney (2001) investigated the degree to which one-word utterances could bootstrap lexical segmentation of two - and threeword utterances. Once identified as units, items in one-word utterances could allow segmentation of longer utterances in which these units also appear. Results from this analysis reveal a high degree of overlap between one- as well as two- and three-word utterances. Almost one third of the lexical items used were common in one- and two-word utterances. Thus, in one third of two-word utterances, infants could be expected to find a piece of given information. Forty percent of the total lexicon which comprised two- and three-word utterances was common. Finally, almost a third of lexical items found in one- and three-word utterances were common to both utterance lengths. Therefore, there is a strong tendency for short utterances to use a common lexical set, which should enable relatively easy segmentation of items in the speech stream (Bernstein Ratner \& Rooney, 2001: 74-75).

Other studies have found similar results in English as well. Brent \& Siskind (2001) found that $9 \%$ of utterances child-directed speech consisted of isolated words, of which $27 \%$ occurred twice or more in neighbouring utterances. Fernald \& Morikawa (1993) also found similar proportions: about $9 \%$ of the utterances spoken by American and Japanese mothers were made up of one word. Other studies have provided evidence in the same lines (Aslin et al., 1996; Siskind, 1996; Van de Weijer, 1998).

Furthermore, empirical evidence also suggests that after hearing words in isolation, infants can recognize them easily when they appear within sentences (Bortfeld, Morgan, Golinkoff \& Rathbun, 2005; Gout, Christophe \& Morgan, 
2004; Houston \& Jusczyk, 2000; Jusczyk \& Aslin, 1995). More interestingly, some studies have even shown that the use of single-word utterances on the part of mothers is linked to vocabulary development in the child's output later on. Brent and Siskind (2001) found that $75 \%$ of 18 -month-olds' first words had previously appeared in isolation in child-directed speech. Besides, the frequency of hearing a word in isolation (but not the frequency of hearing a word overall) seems to be the only predictor of the child's later word use (Ninio, 1992).

Thus, these data suggest that the kind of structural regularities found in English child-directed speech (i.e. in particular, utterance length and lexical redundancy) provide valuable information for preverbal children when they face the task of finding word boundaries in the stream of speech. However, the word-segmentation problem is not specific of the English language exclusively. Although very little empirical evidence across different languages is available, some studies (e.g. Chemla, Mintz, Bernal \& Cristophe, 2009; Feijóo, Serrat \& Muñoz, 2011; Fernald and Morikawa, 1993; Monaghan, Christiansen \& Chater, 2007) reveal that child-directed speech exhibits significant cross-linguistic differences to which language learners should be equally sensitive, since they are assumed to ultimately attain a complete mastery of their native languages. In Jusczyk's words,

(...) the cues that work best for finding word boundaries in English are not necessarily the ones that work best for another language. In fact, learning to pick up the right set of cues that works best for one's own native language, as opposed to another, is a classic case of perceptual learning. The combination of cues that one uses is specific, in much the same way that the cues that wine connoisseurs use to identify different wines would not necessarily transfer to tasting different teas or beers (Jusczyk, 1997: 198-199).

The present study undertakes an examination of Catalan child-directed speech. In particular, the speech to which several Catalan-learning children were exposed was analyzed in order to test whether Catalan child-directed speech presents the same kind of characteristics as English child-directed speech, so that the conclusions drawn by earlier studies can be generalized to other languages as well. Details of the study are presented below.

\section{METHODOLOGY}

In order to test whether the structural simplicity found in child-directed speech was specific of English, or whether it corresponded to a rather general aspect of child-directed speech across languages, we carried out an utterance length analysis and lexical redundancy analysis using data from Catalan child-directed speech. 
The data were obtained from the Serra-Solé corpus available in the CHILDES database (MacWhinney, 2000).

The whole of the Serra-Solé longitudinal corpus includes 10 children but, for the present study, only the transcriptions of five children (i.e. those who were Catalan monolingual speakers) were considered. They were videotaped at their homes in spontaneous interaction with a familiar adult, usually the mother, in sessions of 30 to 45 minutes. All the children belong to middle-class families.

The children were videotaped monthly from 1 to 4 years of age. However, the focus of our study was the type of language that was addressed to children at the earliest stages of their language development process (i.e. before they were completely able to segment the ambient language into word-like units). Thus, not all transcriptions were considered and the ones where each child was approximately beyond 22 months of age were discarded. Table I shows a summary of the age at which each child was taken for the present analysis, as well as the resulting size of each corpus that was considered.

Table I. Corpus size and selected age range.

\begin{tabular}{lcccc}
\hline Child's name & $\begin{array}{c}\text { Age at first } \\
\text { transcription }\end{array}$ & $\begin{array}{c}\text { Age at last } \\
\text { transcription }\end{array}$ & Total types & Total tokens \\
\hline Pep & 13 months & 20 months & 312 & 1,330 \\
Alvar & 14 months & 20 months & 114 & 337 \\
Guillem & 13 months & 20 months & 148 & 472 \\
Gisela & 19 months & 20 months & 161 & 964 \\
Laura & 19 months & 21 months & 379 & 3,616 \\
\hline
\end{tabular}

Therefore, the total size of the resulting corpus after the age selection was made was 1,114 types and 6,719 tokens. From here, all utterances spoken by parents and caregivers were included only, and utterances spoken by the child were excluded from the analysis, since our study was based on the kind of language to which children are exposed, and not to the kind of language that children used themselves.

A total of 8,084 child-directed speech utterances were obtained, which were then analyzed in terms of length as measured by number of words in each utterance using the WDLEN utility of the CLAN program. After that, a lexical overlap analysis was also carried out with all those utterances which were made up of a maximum of three words using the FREQ utility of the CLAN program.

A further analysis was also carried out with one-word utterances only using the FREQ utility of the CLAN program as well, in order to explore the kind of words 
that are most likely to be found in isolation in Catalan child-directed speech. The purpose of this analysis was to test whether the words-in-isolation strategy would equally favor all words from all grammatical categories, or whether, on the contrary, most words found in isolation belonged just to a specific grammatical category such as noun or verb. The results of these analyses are presented in the following section.

\section{RESULTS}

The total of the 8,084 Catalan child-directed speech utterances obtained from the corpus preparation were analyzed in terms of length and lexical complexity. As far as length of utterance is concerned, the results found in Catalan were very similar to the ones found in English (Bernstein Ratner \& Rooney, 2001; Brent and Siskind, 2001). The results from this analysis are shown in Table II. As the table shows, most of the utterances found in the corpus (i.e. about $71 \%$ ) could be considered to be very short utterances, that is, they were made up of three words or less. As a consequence, just about $29 \%$ of the utterances to which the Catalan children from this study were exposed to were longer than three words.

Table II. Results of utterance length analysis.

\begin{tabular}{lcccc}
\hline & $\begin{array}{c}\text { One-word } \\
\text { utterances }\end{array}$ & $\begin{array}{c}\text { Two-word } \\
\text { utterances }\end{array}$ & $\begin{array}{c}\text { Three-word } \\
\text { utterances }\end{array}$ & $\begin{array}{c}\text { Long utterances } \\
(>3 \text { words })\end{array}$ \\
\hline Total & 2,674 & 1,761 & 1,313 & 2,336 \\
Proportion & 0.33 & 0.22 & 0.16 & 0.29 \\
\hline
\end{tabular}

Furthermore, a type/token ratio of all the very short utterances was worked out in order to check the degree of lexical variety found in Catalan child-directed speech. Such analysis revealed a very high degree of lexical redundancy, even higher than the one found for the equivalent English data. Thus, while the type/token ratio in English was 0.209 (Bernstein Ratner \& Rooney, 2001), the equivalent Catalan data showed a type/token ratio of 0.149 . Such results of lexical redundancy found in very short utterances are in sharp contrast with the high degrees of lexical variety found in adult-directed speech (e.g. about 0.45 for English).

Besides utterance length, the lexical complexity of very short utterances in Catalan child-directed speech was also analyzed. Thus, a lexical overlap analysis of Catalan maternal utterances was carried out using similar methodology as the one from previous studies with English data. In this case, the data obtained in the present study confirmed the results obtained from the English corpus by Bernstein 
Ratner \& Rooney (2001), as shown in Figure 1.

As seen in the figure, utterances of different lengths share a considerable amount of lexical items (i.e. types). This high degree of lexical redundancy might be a valuable source of information for preverbal children throughout their language acquisition process. Words in Catalan have considerable chance of being found in isolation in child-directed speech. Those same words are then subsequently found in slightly longer strings of speech. So, once learned when presented in isolation, those lexical items might serve as bootstraps for the acquisition of new units found in longer strings.

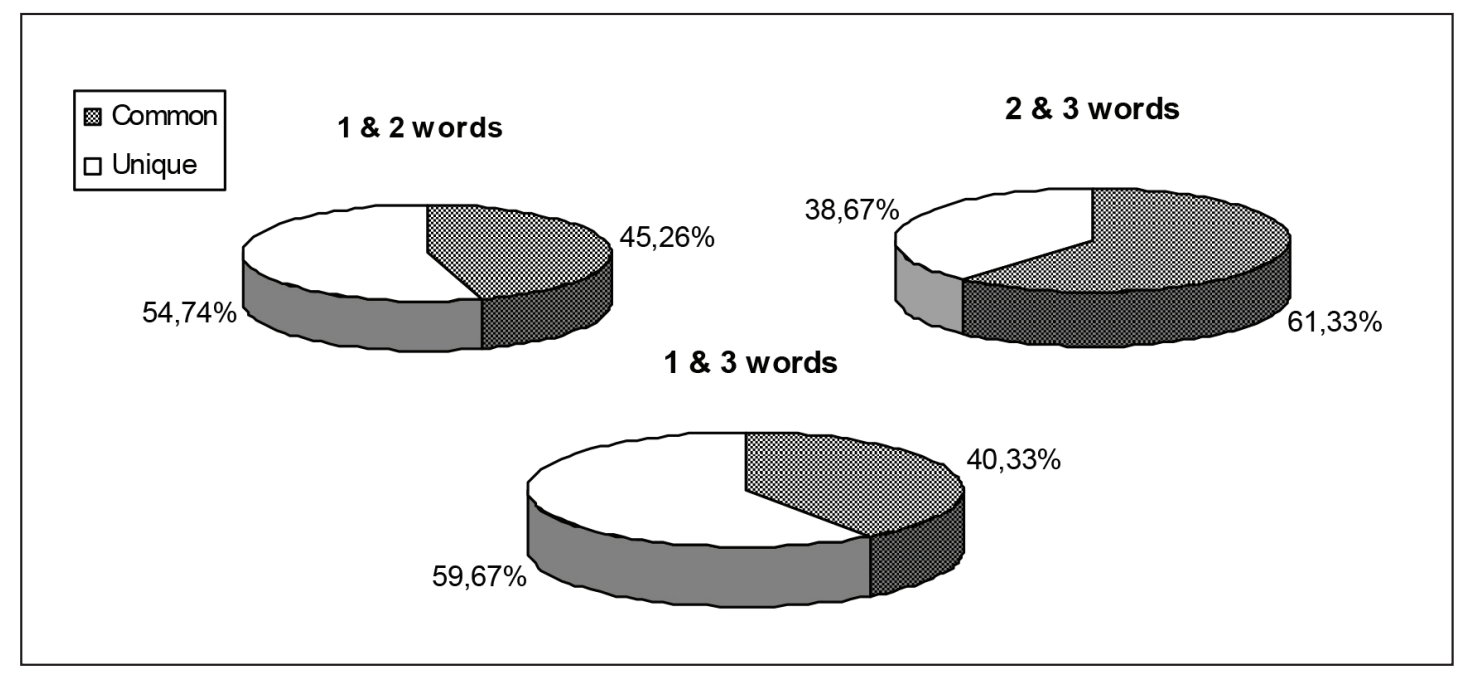

Figure 1. Proportions of lexical overlap in very short utterances from Catalan child-directed speech.

However, a closer look should be taken to the kind of words that are most likely to be found in isolation. Therefore, an analysis of all one-word utterances found in the Catalan corpus was also conducted, in order to test exactly which parts of speech are most commonly found in isolation, and thus, to see whether the facilitation effects provided by child-directed speech would be equally balanced across all grammatical categories. Results from this analysis are shown in Figure 2.

As shown in Figure 2, the facilitation effects provided by the presentation of lexical items in isolation bring about a clear disproportion between open and closed-class items. A type frequency analysis gave a total of $90.26 \%$ open-class words presented in isolation, versus $4.12 \%$ of closed-class items. One would argue that a type frequency analysis might not be relevant to compare the occurrence of open and closed-class items, since closed-class items have typically low type frequencies of occurrence, but high token frequencies. However, a token frequency analysis rendered similar results (i.e. $83.98 \%$ open-class words versus $4.54 \%$ 
closed-class words presented in isolation).

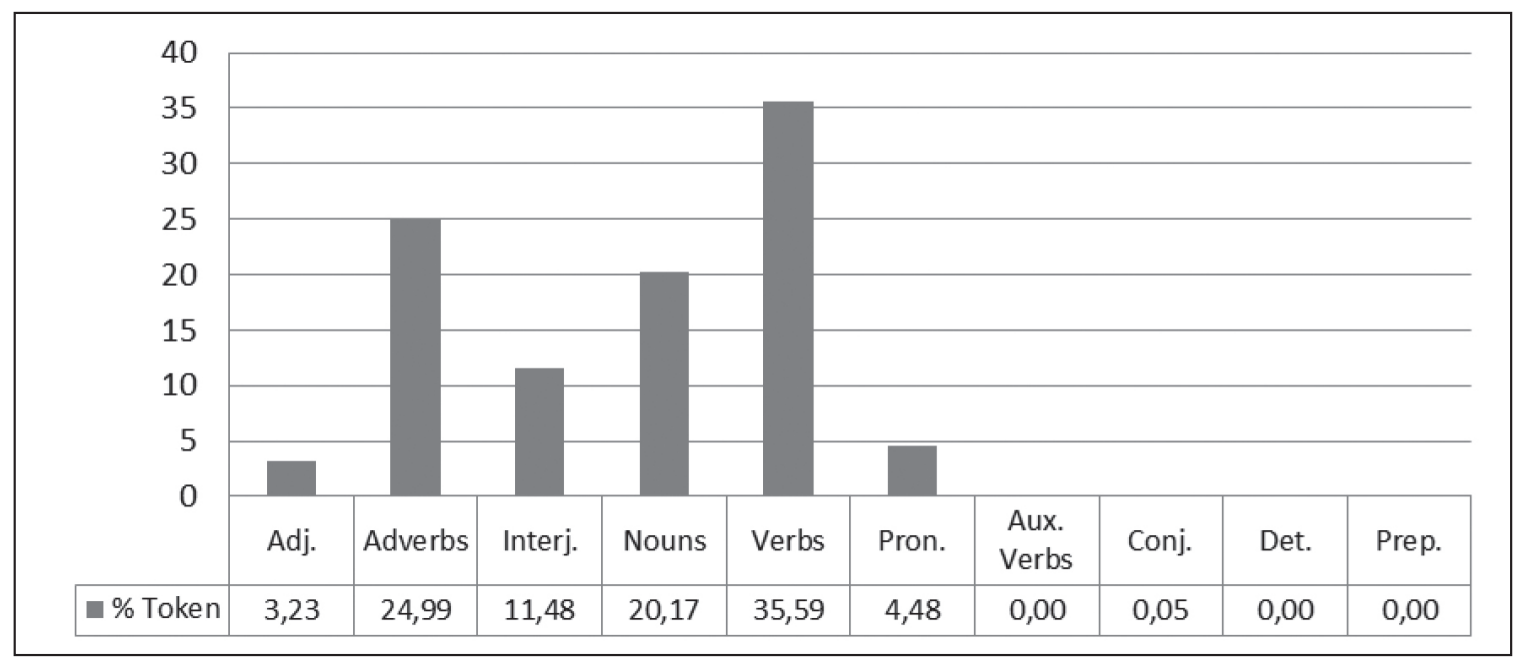

Figure 2. Token frequency and grammatical category of words in isolation in Catalan child-directed speech.

No isolated determiners, prepositions or auxiliary verbs were found at all in any of the single-word utterances. There was only an instance of an isolated conjunction, the conjunction però (i.e. Eng. 'but'), which was found in isolation because the speaker who uttered it stopped her utterance at the beginning and finished her message after a long pause in a new utterance. Thus, pronouns were the only closed-class items which were sometimes found in isolation. Note, however, that pronouns are precisely the only kind of closed-class items that can occur in isolation without resulting in ungrammatical utterances.

Therefore, children can benefit from the facilitation effects of child-directed speech for the segmentation of open-class words only. Of these, nouns and verbs are clearly favoured over the other open-class words. In particular, verbs were far more frequent than nouns. Previous analysis of English child-directed speech, however, suggest that nouns appear disproportionately more often than verbs in maternal single-word utterances (Goldfield, 1993). However, such advantage of nouns over verbs appears when we consider type frequencies and not token frequencies (Feijóo, 2010).

Furthermore, one should also bear in mind that Catalan is a pro-drop language and overt subject pronouns are not required. In the Catalan corpus under analysis, most verbs occurred in the imperative, in the form of commands addressed to the children in an attempt to get the children integrated in the interaction (e.g. vine 'come', seu 'sit down', etc.). Besides, some Catalan transitive verbs were used intransitively by mothers when the object was understood by the context (e.g. menja 'eat', escolta 'listen', etc.). As a pro-drop language, Catalan makes it possible for 
verbs to appear in isolation in these contexts. This might be the reason why verbs appear more frequently used in isolation than nouns.

\section{DISCUSSION AND CONCLUSIONS}

Given the evidence provided by the data presented in this study, the conclusion can be drawn that utterances in Catalan child-directed speech are predominantly short and lexically redundant, with a very high degree of lexical overlap from utterance to utterance. Such structural cues might, therefore, provide infant language learners with very useful information about the location of word boundaries in the speech stream.

Thus, the structural properties that characterize child-directed speech, especially utterance length and lexical redundancy, provide invaluable help for children attempting to locate word boundaries in their language-acquisition process. However, although the facilitation effects provided by child-directed speech cannot be denied, a complete account of the word-segmentation problem as a whole cannot be based just on the properties of the environmental linguistic input.

As seen before, there are many words in Catalan which are ungrammatical in isolation (i.e. determiners, conjunctions, etc.). Therefore, it is very unlikely that any language learner will ever find them presented that way. It is important to bear in mind that children are exposed to simplified input, but such simplifications and modifications never generate ungrammatical utterances. The results from this study reveal that it is mostly open- class words which are likely to be found in isolation. Even within open-class words, it is mostly nouns and verbs that typically occur in single-word utterances. Yet Catalan learning infants should equally locate the word boundaries of all kinds of words. To solve that problem, the kind of very short utterances found in child-directed speech only offer a partial solution.

Furthermore, the assumption that the answer to the word-segmentation problem as a whole lies in the information available in child-directed speech places the burden of the task on the speakers generating the child's language input. However, some mothers do not use words in isolation, even in situations where they are explicitly teaching new vocabulary to their children (Woodward \& Aslin, 1990). More generally, not all children in all languages are exposed to modified childdirected speech, that is, not all cultures talk to children the way occidental mothers do (however, see Lieven, 1994) for a review on common aspects of language addressed to children across different cultures).

In addition, the results of the present study suggest that information relevant for word segmentation is available in the kind of language that children hear, but these results say nothing about children's sensitivity to that information. The empirical evidence available so far suggests that children have proved to be able to 
parse speech and find word-like units using suprasegmental cues available in fluent streams of speech (Cutler, 1996; Echols, 2001; Jusczyk, Houston \& Redanz, 1999; Morgan, Shi \& Allopenna, 1996; Swingley, 2005), as well as using powerful statistical learning mechanisms (Johnson \& Jusczyk, 2001; Pelucchi, Hay \& Saffran, 2009; Saffran, Aslin \& Newport, 1996; Thiessen \& Saffran, 2003). Thus, speech segmentation should be even easier for children when the information they receive contains cues that facilitate the task. Further research is still needed to test whether Catalan-learning infants do actually attend to the kind of linguistic cues that are available in child-directed speech and whether or not they use them productively in word-segmentation tasks.

Therefore, although the availability of cues for word segmentation in childdirected speech cannot be denied, it is definitely not the only solution to the word-segmentation task or to language acquisition in general. However, the combination of the facilitation effects provided by child-directed speech, together with other powerful learning mechanisms that children possess (i.e. sensitivity to acoustic cues or statistical learning mechanisms) might ultimately help children succeed in word-segmentation tasks. In fact, Lew-Williams, Pelucchi \& Saffran (2011) have provided evidence that isolated words and longer utterances act in concert to facilitate infants' statistical learning. Thus, infants who were exposed to stimuli containing words both in fluent speech and in isolation detected the statistical regularities of their component syllables more successfully than infants who were exposed to the same words but only in fluent speech. Therefore, statistical learning mechanisms may in fact benefit from the type of simplifications in utterance length which are characteristic of child-directed speech. All in all, isolated words may then have positive consequences for language learning.

\section{REFERENCES}

Anderson, S.R. \& Lightfoot, D.W. (1999). The human language faculty as an organ. Annual Review of Physiology, 62, 697-722.

Anderson, S.R. \& Lightfoot, D.W. (2002). The language organ: Linguistics as cognitive physiology. Cambridge: Cambridge University Press.

Aslin, R.N., Woodward, J.Z., LaMendola, N.P. \& Bever, T.G. (1996). Models of word segmentation in fluent maternal speech to infants. In J. L. Morgan \& K. Demuth (eds.), Signal to syntax: Bootstrapping from speech to grammar in early acquisition (pp. 115-134). Mahwah, NJ: Erlbaum.

Bernstein Ratner, N. (1996). From 'Signal to Syntax': But what is the nature of the signal? In J.L. Morgan \& K. Demuth (eds.), Signal to syntax: Bootstrapping from speech to grammar in early acquisition (pp. 135-150). Mahwah, NJ: Erlbaum. 
Bernstein Ratner, N. \& Rooney, B. (2001). How accessible is the lexicon in Motherese? In J. Weissenborn \& B. Höhle (eds.), Approaches to bootstrapping: Phonological, lexical, syntactic and neurophysiological aspects of early language acquisition (pp. 71-78). Amsterdam: John Benjamins.

Bortfeld, H., Morgan, J.L., Golinkoff, R.M. \& Rathbun, K. (2005). Mommy and me: Familiar names help launch babies into speech-stream segmentation. Psychological Science, 16, 298-304.

Brent, M.R. \& Siskind, J.M. (2001). The role of exposure to isolated words in early vocabulary development. Cognition, 81, 33-44.

Chemla, E., Mintz, T.H., Bernal, S. \& Cristophe, A. (2009). Categorizing words using 'frequent frames': What cross-linguistic analyses reveal about distributional acquisition strategies. Developmental Science, 12 (3), 396-406.

Chomsky, N. (1984). Modular approaches to the study of the mind. San Diego: San Diego State University Press.

Cole, R.A. \& Jakimik, J. (1980). A model of speech perception. In R.A. Cole (ed.), Perception and production of fluent speech (pp. 133-163). Hillsdale, NJ: Lawrence Erlbaum Associates.

Crain, S. \& Pietroski, P. (2001). Nature, nurture and universal grammar. Linguistics and Philosophy, 24, 139-186.

Cutler, A. (1996). Prosody and the word boundary problem. In J.L. Morgan \& K. Demuth (eds.), Signal to syntax: Bootstrapping from speech to grammar in early acquisition (pp. 87-99). Mahwah, NJ: Erlbaum.

Echols, C.H. (2001). Contributions of prosody to infants' segmentation and representation of speech. In J. Weissenborn \& B. Höhle (eds.), Approaches to bootstrapping: Phonological, lexical, syntactic and neurophysiological aspects of early language acquisition (pp. 25-46). Amsterdam: John Benjamins.

Feijóo, S. (2010). Learning from the input: Syntactic, semantic and phonological cues to the noun category in English. Doctoral dissertation, Universitat de Barcelona, Spain.

Feijóo, S., Serrat, E. \& Muñoz, C. (2011). The usefulness of morphosyntactic frames in Spanish and English noun categorization. Poster presented at the ADYLOC International Conference, Paris.

Fernald, A. \& Morikawa, H. (1993). Common themes and cultural variations in Japanese and American mothers' speech to infants. Child Development, 64, 637-656.

Fisher, C. \& Church, B.A. (2001). Implicit memory support for language acquisition. In J. Weissenborn \& B. Höhle (eds.), Approaches to bootstrapping: Phonological, lexical, syntactic and neurophysiological aspects of early language acquisition (pp. 47-69). Amsterdam: John Benjamins.

Goldfield, B. (1993). Noun bias in maternal speech to one-year olds. Journal of Child Language, 20, 85-99. 
Gout, A., Christophe, A. \& Morgan, J.L. (2004). Phonological phrase boundaries constrain lexical access II: Infant Data. Journal of Memory and Language, 51, 548-567.

Hilferty, J. (2003). In defense of grammatical constructions. Doctoral dissertation, Universitat de Barcelona, Spain.

Houston, D.M. \& Jusczyk, P.W. (2000). The role of talker-specific information in word segmentation by infants. Journal of Experimental Psychology: Human Perception and Performance, 26, 1570-1582.

Johnson, E.K. \& Jusczyk, P.W. (2001). Word segmentation by 8-month-olds: When speech cues count more than statistics. Journal of Memory and Language, 44, 548-567.

Jusczyk, P.W. (1997). The discovery of spoken language. Cambridge, MA: The MIT Press.

Jusczyk, P.W. \& Aslin, R.N. (1995). Infants' detection of the sound patterns of words in fluent speech. Cognitive Psychology, 29, 1-23.

Jusczyk, P.W., Houston, D.M. \& Redanz, N. (1999). The beginnings of word segmentation in English-learning infants. Cognitive Psychology, 39, 159-207.

Kuhl, P.K. (2000). A new view of language acquisition. Proceedings of the National Academy of Science, 97 (22), 11850-11857.

Lew-Williams, C., Pelucchi, B. \& Saffran, J. R. (2011). Isolated words enhance statistical language learning in infancy. Developmental Science, 14, 1323-1329.

Lieven, E. (1994). Crosslinguistic and crosscultural aspects of language addressed to children. In C. Gallaway \& B.J. Richards (eds.), Input and interaction in language acquisition (pp. 56-73). Cambridge: CUP.

MacWhinney, B. (2000). The CHILDES Project: Tools for Analyzing Talk. Third edition. Mahwah, NJ: Lawrence Erlbaum Associates.

Monaghan, P., Christiansen, M.H. \& Chater, N. (2007). The phonological-distributional coherence hypothesis: Cross-linguistic evidence in language acquisition. Cognitive Psychology, 55, 259-305.

Morgan, J.L., Shi, R. \& Allopenna, P. (1996). Perceptual bases of rudimentary grammatical categories: toward a broader conceptualization of bootstrapping. In J. L. Morgan \& K. Demuth (eds.), Signal to syntax: Bootstrapping from speech to grammar in early acquisition (pp. 262-293). Mahwah, NJ: Erlbaum.

Ninio, A. (1992). The relation of children's single word utterances to single word utterances in the input. Journal of Child Language, 19, 87-110.

Pelucchi, B., Hay, J.F. \& Saffran, J.R. (2009). Statistical learning in a natural language by 8 month-old infants. Child Development, 80 (3), 674-685.

Plunkett, K. (1993). Lexical segmentation and vocabulary growth in early language acquisition. Journal of Child Language, 20, 43-60. 
Sachs, J., Brown, R. \& Salerno, R.A. (1976). Adults' speech to children. In W. von Raffler-Engel \& Y. LeBrun (eds.), Baby talk and infant speech (special issue). Neurolinguistics, 5, 240-245.

Saffran, J.R., Aslin, R.N. \& Newport, E.L. (1996). Statistical learning by 8-month-old infants. Science, 274, 1926-1928.

Saffran, J.R., Newport, E.L. \& Aslin, R.N. (1996). Word segmentation: The role of distributional cues. Journal of Memory and Language, 35, 606-621.

Siskind, J.M. (1996). A computational study of cross-situational techniques for learning word-to-meaning mappings. Cognition, 61, 39-91.

Snow, C.E. \& Ferguson, C.A. (eds.). (1977). Talking to children: Language input and acquisition. Cambridge: Cambridge University Press.

Swingley, D. (2005). Statistical clustering and the contents of the infant vocabulary. Cognitive Psychology, 50, 86-132.

Thiessen, E.D. \& Saffran, J.R. (2003). When cues collide: Use of stress and statistical cues to word boundaries by 7- to 9-month-old infants. Developmental Psychology, 39, 706-716.

Thiessen, E.D. \& Saffran, J.R. (2007). Learning to learn: Infants' acquisition of stress-based strategies for word segmentation. Language Learning and Development, 3 (1), 73-100.

Thiessen, E.D., Hill, E. A. \& Saffran, J.R. (2005). Infant-directed speech facilitates word segmentation. Infancy, 7 (1), 53-71.

Van de Weijer, J. (1998). Language input for word discovery. Nijmegen: Max Planck Institute for Psycholinguistics.

Werker, J.F., Pons, F., Dietrich, C., Kajikawa, S., Fais, L. \& Amano, S. (2007). Infant-directed speech supports phonetic category learning in English and Japanese. Cognition, 103, 147-162.

Woodward, J. Z. \& Aslin, R.N. (1990). Segmentation cues in maternal speech to infants. Paper presented at 7 th biennial meeting of the International Conference on Infant Studies, Montréal, Quebec, Canada.

Zangl, R. \& Mills, D.L. (2007). Increased brain activity to infant-directed speech in 6- and 13-month-old infants. Infancy, 11, 31-62. 